\title{
The Downregulation of Growth-associated Proteins in Motoneurons at the Onset of Synapse Elimination Is Controlled by Muscle Activity and IGF1
}

\author{
Pico Caroni and Marius Becker \\ Friedrich Miescher Institute, $\mathrm{CH}-4002$ Basel, Switzerland
}

\begin{abstract}
Axonal growth during development and regeneration coincides with the expression of growth-associated proteins (GAPs), including GAP-43 and tubulin- $\alpha 1$. Following contact with the target region and synaptogenesis, GAPs are downregulated. However, high levels of GAP-43 are expressed in some neurons in the adult CNS, indicating that its function may not be restricted to axonal growth.
\end{abstract}

To define the type of signals that regulate GAP levels during development, we have determined whether GAP downregulation coincides with a defined phase of synapse development and whether it is controlled by the postsynaptic target. Levels of GAP-43 mRNA in spinal motoneurons and protein at the neuromuscular junction were analyzed in the developing neuromuscular system of chick and rat. In both species, GAP-43 mRNA declined rapidly at a time corresponding to the onset of synapse elimination, and nerve terminal GAP-43 immunoreactivity became undetectable with a delay of 2-3 d. In rat motoneurons, GAP-43 and tubulin$\alpha 1$ mRNA levels declined with a similar time course, indicating that at least two GAPs are downregulated at the same time. Blockade of neuromuscular transmission with either a pre- or a postsynaptically acting toxin prevented GAP downregulation, indicating that target activity affects GAP mRNA levels in motoneurons. Finally, counteracting the activitydependent decline of muscle insulin-like growth factors during synapse elimination by local subcutaneous injections prevented motoneuron GAP downregulation, suggesting that these growth factors may be involved in the regulation of motoneuron GAPs by the muscle.

These results demonstrate that motoneurons undergo target-sensitive changes in GAPs at the onset of synapse elimination. In addition, these results raise the possibility that termination of a presynaptic growth mode may be a prerequisite for synapse elimination.

The outgrowth of axons and dendrites is under precise temporal and spatial control during nervous system development. According to the growth-associated protein (GAP) hypothesis (Skene

\footnotetext{
Received Feb. 6, 1992; revised Apr. 23, 1992; accepted Apr. 30, 1992.

We are grateful to V. Witzemann (Max Planck Institute for Medical Research, Heidelberg, Germany; purified botulinum toxin A) and K. Buckley (Harvard University, Cambridge, MA; antibody SV2) for gifts of reagents, and to C. Schneider and F. Widmer for help with some of the experiments. We are especially grateful to A. Matus, D. Monard, and F. Widmer for critically reading the manuscript.

Correspondence should be addressed to Pico Caroni, Friedrich Miescher Institute, P.O. Box 2543, CH-4002 Basel, Switzerland.

Copyright (C) 1992 Society for Neuroscience $0270-6474 / 92 / 123849-13 \$ 05.00 / 0$
}

and Willard, 1981), axonal growth requires the expression of a spccialized set of neuronal gencs. The expression of GAP gencs would correlate with axonal growth, and termination of the program would follow contact with the target region. An additional aspect of the GAP hypothesis is the reinduction of GAPs during regenerative growth in the PNS (Skene and Willard, 1981; Skene, 1989). Neuronal gene products that might be included in the GAP class include tubulin isoforms [tubulin- $\alpha 1$ (T $\alpha 1$ ), $\beta 2$-tubulin], GAP-24, GAP-50, and the cell adhesion protein N-CAM (Miller and Milner, 1987, 1989; Skene, 1989; Tetzlaff et al., 1991). The protein that has been most extensively investigated in this context, however, is GAP-43, a cortical GAP of the nervous system (Benowitz and Routtenberg, 1987; Skene, 1989; Coggins and Zwiers, 1991). GAP-43 is found in most, and possibly in all neurons when they extend their axons, and it is enriched in axonal growth cones, where it is a major protein kinase C substrate (Jacobson et al., 1986; Meiri et al., 1986; Skene et al., 1986; Nelson et al., 1989). In spite of cxtensive studies, the function of GAP-43 in axonal growth is presently not clear.

If a neuronal axonal growth program exists, one would like to know whether potentially related processes like collateral sprouting, reactive nerve sprouting in the vicinity of a deafferented target region, and possibly even some forms of plasticity related to learning might be related to axonal growth in molecular terms. In addition, one would like to know how flexible such a growth program may be. While this latter question is still open, a considerable body of evidence suggests that at least some GAPs are also involved in processes distinct from growth during development or regeneration. Thus, T $\alpha 1$ mRNA is induced in unlesioned neurons involved in reactive sprouting, and induction can also be brought about by the local injection of NGF (Matthew and Miller, 1990). These results demonstrate that cell body reactions involving GAPs can be induced in intact adult neurons by events in the neuron's periphery. Data supporting similar conclusions were obtained for GAP-43 in the adult hippocampus (Moslich et al., 1991). Analysis of GAP-43 mRNA and protein levels during development and in the adult has yielded provocative findings suggesting possible links between the presence of this GAP and plasticity phenomena (Benowitz and Routtenberg, 1987; Neve et al., 1988; Neve and Bear, 1989). A possible related finding is that GAP-43 phosphorylation is prominent in conditions leading to long-term potentiation (Benowitz and Routtenberg, 1987; Nelson et al., 1989). Finally, it was soon realized that levels of some GAPs did not decline immediately after target contact during development. Decline of GAP-43 and T $\alpha 1$ was observed at remark- 
ably late stages (Miller and Milner, 1987; Hesselmans et al., 1989; Moya et al., 1989; Neve and Bear, 1989; Skene, 1989; Reynolds et al., 1991), suggesting that aspects of a neuronal growth mode might be maintained, possibly implying that they are required for further processes such as rearrangements of synaptic connections.

In this study we have attempted to define the type of signals that regulate GAP levels during development. We have first determined whether the developmental downregulation of GAP43 protein and mRNA levels coincides with a defined phase of synapse development. For this purpose, we analyzed GAP-43 levels in the neuromuscular system, where the developmental schedule has been described in great detail (Dennis, 1981; Bennet, 1983), and where the separation of presynaptic neuronal cell bodies in the ventral horn of the spinal cord from the synapses in skeletal muscle allows independent analysis and manipulation of central and peripheral events. We have compared the behavior of GAP-43 in the chick and the rat, two species with diffcrent developmental schedules, in order to establish a possible correlation between neuromuscular junction ( $\mathrm{nmj}$ ) development and GAP-43 levels. Further, we studied the behavior of T $\alpha 1$ mRNA in the rat neuromuscular system to determine whether downregulation timing is peculiar to GAP-43, or whether a group of GAP genes might be regulated in a similar manner. Finally, we determined whether the developmental downregulation of GAPs in motoneurons is cell autonomous, or whether it is governed by events in the target region by interfering with neuromuscular transmission or by manipulating growth factor levels in muscle.

We report that GAP-43 and T $\alpha 1$ are downregulated in motoneurons at the onset of the synapse elimination process. Preor postsynaptic blockade of neuromuscular transmission prevented the downregulation of GAP-43 and T $\alpha 1$, demonstrating that GAP mRNA levels in motoneurons are regulated by target activity, and suggesting that activity-dependent target-derived factors may affect the expression of GAPs in presynaptic cell bodies. Finally, we show that counteracting the developmental decline of muscle insulin-like growth factor 1 (IGF1) during synapse elimination is sufficient to prevent GAP-43 and T $\alpha 1$ downregulation in spinal motoneurons.

\section{Materials and Methods}

Reagents. Long- ${ }^{3}$ R-IGFl was from GroPep, Adelaide, Australia (stock solution: $1 \mu \mathrm{g} / \mathrm{ml}$ in PBS with $0.1 \%$ BSA); purified botulinum toxin A was a kind gift of V. Witzemann, Max Planck Institute for Medical Research, Heidelberg, Germany (stock solution: $260 \mathrm{pg} / \mathrm{ml}$ in PBS with $0.1 \%$ BSA); $\alpha$-bungarotoxin was from Sigma (stock solution: $3.3 \mu \mathrm{g} /$ $\mathrm{ml}$ in PBS with $0.1 \% \mathrm{BSA}$ ). Digoxigenin-11-UTP, alkaline phosphataseconjugated anti-digoxigenin antibody, SP6 and T7 RNA polymerase, and plasmid pSPT19 were from Boehringer Mannheim. Oligonucleotides were synthesized using an Applied Biosystems 308B DNA synthesizer. A 777 base pair (bp) DNA fragment containing the entire coding sequence of chick GAP-43 (Baizer et al., 1990) was isolated with PCR technology from an embryonic day 10 (E10) chick embryo cDNA library. A 601 bp DNA fragment containing the coding sequence of rat GAP-43 (Basi et al., 1987) and a DNA fragment containing 120 bp 3' from the Ava2 site on the $3^{\prime}$ untranslated region of rat tubulin- $\alpha 1$ mRNA (Miller and Milner, 1987) were isolated with PCR technology from a postnatal day 4 (P4) rat brain cDNA library. The identity of the GAP43 and $T \alpha 1$ probes was confirmed by sequencing (Sequenase 2 kit, U.S. Biochemical Corp., Cleveland, $\mathrm{OH}$ ).

Chick GAP-43 was detected with the specific monoclonal antibody 5F10 (Widmer and Caroni, 1990). Monoclonal antibody SV2 detects a synaptic vesicle antigen in chick and rat (Buckley and Kelly, 1985) and was a kind gift of Dr K. Buckley, Harvard University, Cambridge, MA.
A rabbit antiserum to a 12 amino acid synthetic peptide corresponding to the C-terminal end of rat GAP-43 specifically detected rat GAP-43 on immunoblots and yielded labeling patterns of rat nervous system tissue sections that were consistent with it specifically binding to GAP43. FITC-conjugated goat anti-rabbit and goat anti-mouse were from Milan Analytica AG, LaRoche, Switzerland. RITC-conjugated $\alpha$-bungarotoxin was from Molecular Probes, Eugene, OR.

Injection protocols. Sprague-Dawley rats were anesthetized with ether, and one hind limb (thigh) was subjected to one of the following treatments: (1) intramuscular injection of $50 \mu \mathrm{l}$ of carrier (PBS with $0.1 \%$ BSA) containing $13 \mathrm{pg}$ of botulinum toxin A (if required, this treatment was repeated at P14), (2) intramuscular injections cvery second day of $50 \mu \mathrm{l}$ of carrier containing $150 \mathrm{ng}$ of $\alpha$-bungarotoxin, (3) subcutaneous injections every second day of $50 \mu \mathrm{l}$ of carrier containing $50 \mathrm{ng}$ of long${ }^{3} \mathrm{R}-\mathrm{IGF} 1$, or (4) intramuscular injections every second day of carrier alone. Treatments were initiated at $\mathrm{P} 6$, and the contralateral hind limb received corresponding injections of carrier alone. Animals were monitored for signs of paralysis, which always exclusively involved the toxintreated hind limb and were obvious approximately $12 \mathrm{hr}$ after treatment. The lowest doses producing complete local paralysis and not affecting the growth (weight gain) of the animals were selected. Except for the impaired utilization of one hind limb, animals could not be distinguished from untreated siblings in the same cage. Animals treated with long- ${ }^{3} \mathrm{R}-\mathrm{IGF} 1$ could not be distinguished in their behavior from carriertreated or untreated animals. Histological examination of long-3R-IGF1treated muscles revealed elevated numbers of muscle intcrstitial cells, slightly expanded interstitial spaces, and muscle fibers of somewhat reduced diameter. These histological changes were not observed in the contralateral, carrier-treated muscle.

In situ hybridization experiments. Digoxigenin-labeled riboprobes were synthesized in in vitro transcription reactions with probe DNA inserted in the vector pSPT19 and digoxigenin-11-UTP, according to the recommendations of the manufacturer (Boehringer Mannheim). Approximately $10 \mu \mathrm{g}$ of riboprobe were synthesized from $1 \mu \mathrm{g}$ of vector in a $10 \mu \mathrm{l}$ reaction. To reduce nonspecific binding and to improve probe penetration, the labeled riboprobes were hydrolyzed at $\mathrm{pH} 10.2$ in carbonate buffer (Cox and Angerer, 1984) to yield average fragments of $100 \mathrm{bp}$. Length and specificity of the probes were verified by appropriate gel electrophoresis and Northern blotting experiments.

The lumbar section of the spinal cord was carefully dissected and fixed over night in PBS with 4\% paraformaldehyde. After cryoprotection in PBS with $20 \%$ sucrose, spinal cord sections were mounted and 12 $\mu \mathrm{m}$ cryostat sections were cut. Sections were postfixed for $5 \mathrm{~min}$ in PBS with $4 \%$ paraformaldehyde, incubated for $10 \mathrm{~min}$ at room temperature in the presence of $25 \mu \mathrm{g} / \mathrm{ml}$ of self-digested proteinase K (Sigma), postfixed as described above, washed, and dehydrated. Sections were then hybridized for $16 \mathrm{hr}$ at $54^{\circ} \mathrm{C}$ in a solution containing $50 \%$ formamide, $4 \times$ saline-sodium citrate (SSC), $10 \mathrm{mM} \mathrm{NaCl}, 1 \mathrm{mM}$ EDTA, $2 \times$ Denhardt's, $100 \mu \mathrm{g} / \mathrm{ml}$ of yeast RNA (Sigma), and appropriate dilutions (1$4 \mathrm{ng} / \mathrm{ml}$ ) of the digoxigenin-labeled riboprobes. After RNase treatment and high-stringency washing, sections were blocked for $15 \mathrm{~min}$ at room temperature in $100 \mathrm{mM}$ Tris (pH 8.5$), 150 \mathrm{mM} \mathrm{NaCl}$, and $5 \% \mathrm{BSA}$ (T8.5) and then incubated for $1 \mathrm{hr}$ in T8.5 with a 1:750 dilution of the alkaline phosphatase-conjugated anti-digoxigenin antibody. Sections were then washed in T8.5 and processed for color reaction. When appropriate (usually after $30-90 \mathrm{~min}$ ), the phosphatase reaction was stopped and sections were dehydrated, mounted in DePex (BDH Ltd., Poole, UK), and examined and photographed under bright-field illumination. All sections belonging to one experimental set (e.g., GAP-43 mRNA levels in the spinal cord of rats at different stages of development) were processed at the same time and in the same way. This included color reaction time and photography. Fach experimental set was performed at least five times (two to four animals per point). Relative signal intensities for data from different developmental stages were reproducible, whereas background levels varied somewhat between different experiments. Background variations mostly involved all samples from a given experiment, whereas no obvious background differences between spinal cord samples from different developmental stages were detected. Partial correction for background variation was achieved by varying the duration of the color reaction (for all samples from one experimental set). Data from representative experimental sets are shown in the figures.

Immunocytochemistry. Thigh muscle, mainly the quadriceps, was dissected and fixed overnight in PBS with $4 \%$ paraformaldehyde. In the chick, this muscle mainly consists of fast muscle fibers, whereas in the rat it contains a mixed population of fast and slow-type fibers. After 
cryoprotection in PBS with $20 \%$ sucrose, muscles were mounted and $12 \mu \mathrm{m}$ cryostat sections were cut. Sections were then incubated for 30 min at room temperature in PBS with $5 \%$ BSA, $5 \%$ sucrose, and $0.5 \%$ NP-40. To detect chick antigens, muscle sections were incubated overnight at $4{ }^{\circ} \mathrm{C}$ in the presence of antibody $5 \mathrm{~F} 10$ or SV2 in PBS with $1 \%$ BSA, $0.5 \%$ NP- 40 , and $5 \%$ sucrose. Rat muscle sections were exposed to antibody for $3 \mathrm{hr}$ at room temperature in PBS with 1\% BSA and 5\% sucrose. Subsequent washes were in PBS, and second antibody incubations were for $1 \mathrm{hr}$ at room temperature in PBS with $1 \%$ BSA, 5\% sucrose, and $2 \mu \mathrm{g} / \mathrm{ml}$ of RITC- $\alpha$-bungarotoxin. Finally, sections were mounted in Airvol and fluorescent signals were detected with an Axiovert 10 microscope (Carl Zeiss) equipped with appropriate filters. All photographs belonging to an experimental set were taken and processed in the same way and series of experiments were repeated 5-10 times (two to four animals per experimental point). Variations between experimental sets were minor, and data from one representative set of experiments are shown in each figure. Most chick- and rat-derived samples yielded GAP-43 immunoreactivity signals that deviated from the expected intensities as shown in Figures 1 and 3 by less than $1 \mathrm{~d}$ of development. While small variations in GAP-43 downregulation timing between different thigh muscles were observed, they did not appear to be large enough to justify a more detailed study of single thigh muscle types. In addition, some variation within end plates of the same muscle did occur. These variations mostly correlated with end-plate size, suggesting that they were due to individual differences in end-plate maturation.

\section{Results}

GAP-43 downregulation in chick and rat motoneurons coincides with the elimination of polyinnervation at the nmj Intramuscular nerve GAP-43 was analyzed on cryostat sections of chick and rat thigh skeletal muscle by immunocytochemistry at the light microscopic level. In the chick, motoneuron axons reach the developing muscle around E3-E4 and synapses are formed between E6 and E9 (Dahm and Landmesser, 1991). Synapses then develop, new synapses are formed on secondary myotubes, and muscle fibers receive multiple synapses from several motoneurons. From E15 on, polyinnervation of skeletal muscle fibers is eliminated by the stepwise retraction of supernumerary synapse-forming side branches (Bennet, 1983). This process is completed approximately 1 week after birth (E21, or P0). As shown in Figure 1, strong GAP-43 immunoreactivity was detected in chick intramuscular nerves and nmjs between E8 and F15. After E15, nerve GAP-43 signals declined rapidly but nmj GAP-43, as revealed by its colocalization with $\mathrm{ACh}$ receptor $(\mathrm{AChR})$ binding $\alpha$-bungarotoxin, was apparently unchanged up to E18. Strong decline of the nmj GAP-43 signal was then observed: only about $20 \%$ of the end plates displayed significant immunoreactivity at $\mathrm{P} 2$, while essentially all end plates were unlabeled by P7. Therefore, chick nmj GAP-43 declines between E18 and P2, a period that coincides approximately with the progress of synapse elimination.

GAP-43 mRNA was then analyzed in the corresponding motoneurons in the ventral horn columns of the lumbar spinal cord. For this purpose, a nonradioactive detection method based on digoxigenin-labeled riboprobes and on alkaline phosphataseconjugated anti-digoxigenin antibody was applied, thus achieving resolution of the hybridization signals at the single cell level. As shown in Figure 2, strong GAP-43 signals were detected in large spinal cord ventral horn cells from E6-E14 chicks. Size and characteristic distribution of the ventral horn cells displaying some of the strongest signals in the spinal cord indicate that these cells are motoneurons. This figure also shows that, as expected from its ubiquitous expression in neurons, GAP-43 mRNA was detected in many cells in the gray matter, but not in the white matter of the spinal cord. Chick motoneuron GAP-
43 mRNA signals began to decline between E14 and E16 (Fig. $2 f$ ) and were markedly reduced at E18 (Fig. $2 g$ ) and nearly undetectable at E20 (Fig. $2 h$ ). This behavior, including the sharp decline between E15 and E18, was found consistently and indicates that chick motoneuron GAP-43 mRNA levels undergo strong downregulation at a period that corresponds with the onset of the synapse elimination process. Therefore, in chick motoneurons, GAP-43 mRNA was downregulated at the onset of synapse elimination and $\mathrm{nmj}$ levels of GAP-43 declined with a dclay of $2-4 \mathrm{~d}$.

Similar experiments were then performed in the neuromuscular system of the rat. In rat hind limb, skeletal muscle motoneuron processes reach the developing muscle at E11, synapses form from E12 on, and elimination of polyinnervation begins at P8 and is completed at P14 (Brown et al., 1976; Dennis, 1981; Bennet, 1983). As shown in Figure 3, rat hind thigh intramuscular nerve GAP-43 immunoreactivity levels remained similar between $\mathrm{P} 4$ and $\mathrm{P} 8$ but underwent marked reduction between P8 and P14. After P12-P13, GAP-43 immunoreactivity was nearly undetectable and comparable to that of adult nmjs. Like in the chick, and as described by others (Hesselmans et al., 1989; Reynolds et al., 1991), some degree of signal variability was detected between different end plates during the downregulation process, but only a small percentage (less than $5 \%$ ) of the nmjs displayed GAP-43 signals significantly higher than adult levels at P13. Figure 3 also shows that whilc no GAP43 signals could be detected after P12-P13, distinct signals for the synaptic vesicle antigen SV2 (Buckley and Kelly, 1985; Dahm and Landmesser, 1991) could be detected in analogous experiments in P19 skeletal muscle (Fig. $3 h$ ). In fact, SV2 nmj signal intensities did not change significantly between P0 and P90 in rat and between E12 and P7 in chick skeletal muscle (data not shown), indicating that the declines in nmj GAP-43 signals were not due to decreased accessibility of presynaptic antigens in maturing nmjs. This conclusion is further supported by the expression profile of rat motoneuron GAP-43 mRNA (Fig. 4). As in the chick, strong GAP-43 mRNA signals were detected in large ventral horn lumbar spinal cord cells before the period of synapse elimination. Grouping of these cells could frequently be observed, and the groups presumably correspond to motoneuron columns that run longitudinally between segments of the lumbar and sacral spinal cord (e.g., Fig.4d,e). The columns consist of motoneurons innervating separate skeletal muscle types. Rat lumbar spinal motoneuron GAP-43 mRNA levels declined markedly between P8 and P11 (Fig. $4 d-g$ ). The strongest decline was consistently detected between P8 and P10, and GAP-43 message was not detectable above background levels from P11-P12 on.

From these experiments in two species with different developmental schedules, we conclude that, in the neuromuscular system, GAP-43 downregulation coincides with a defined developmental process: motoneuron GAP-43 mRNA levels decline sharply at the onset of the elimination process, and the corresponding GAP-43 protein levels at the $\mathrm{nmj}$ appear to accompany the progress of the elimination process.

\section{At least two different motoneuron GAP mRNAs are downregulated at the onset of synapse elimination}

We next asked whether the late downregulation of motoneuron GAP-43 was specific for this protein, or whether other GAP mRNAs may be regulated in a similar manner. For this purpose 

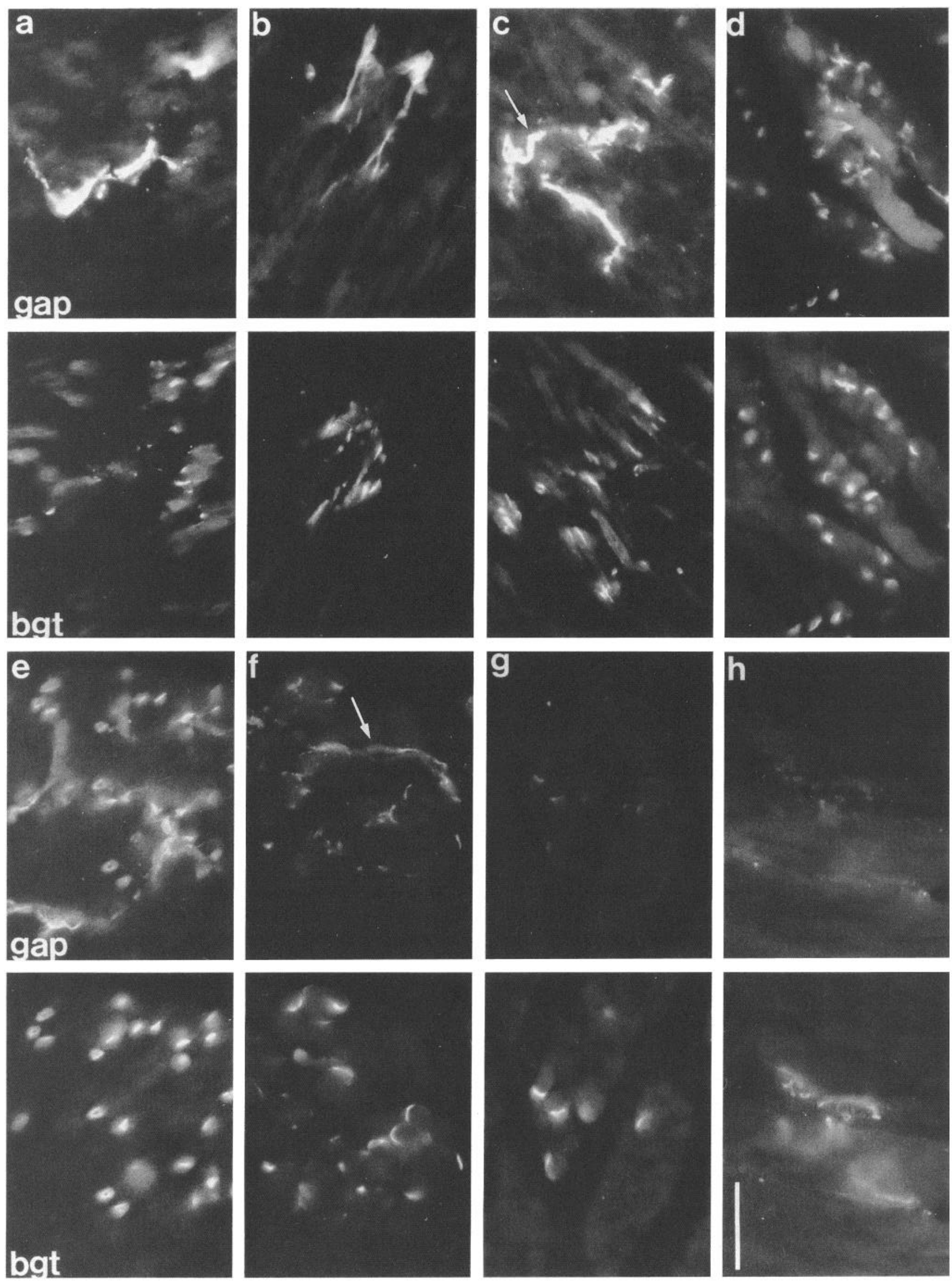

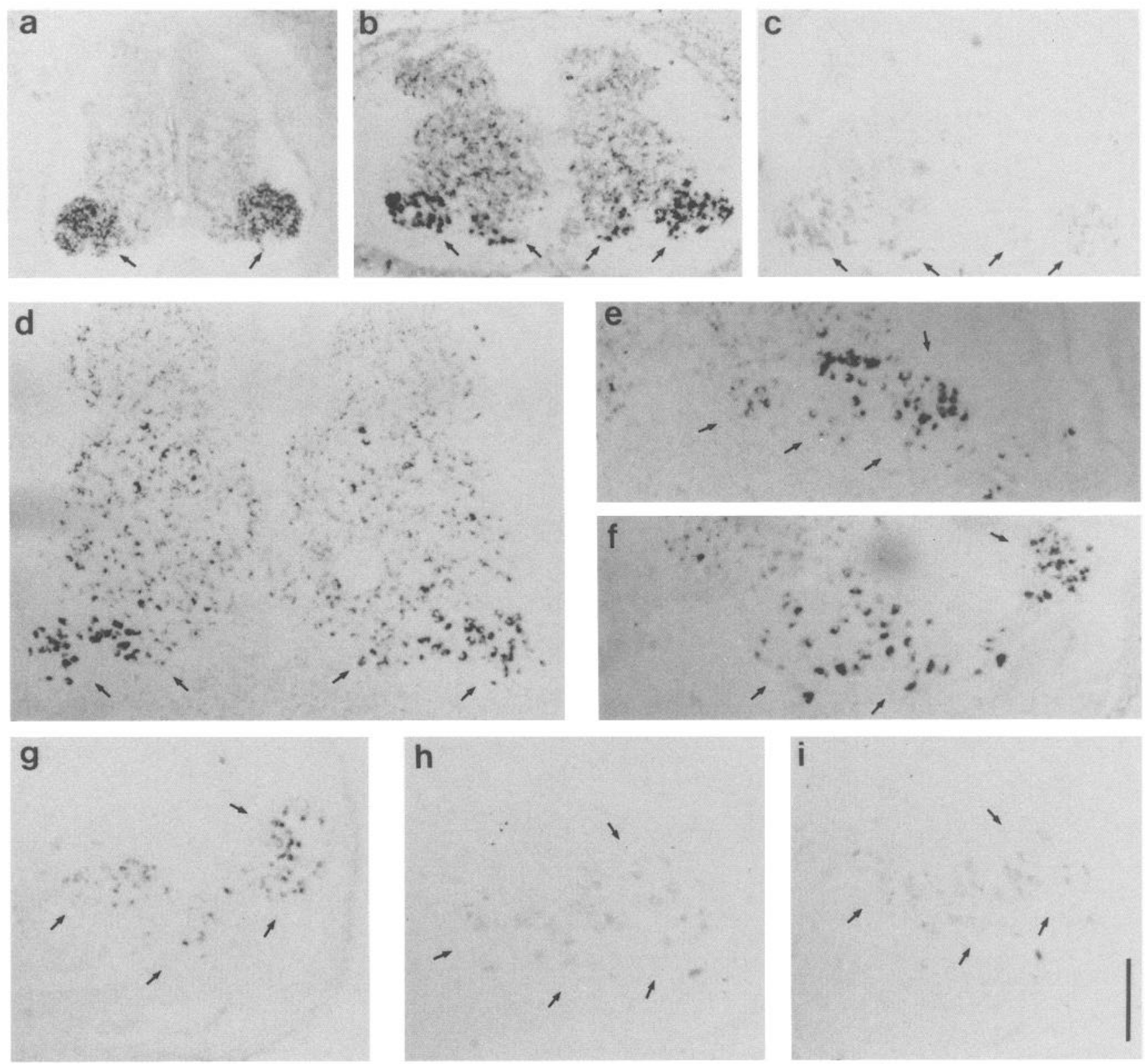

Figure 2. GAP-43 mRNA in the developing chick lumbal spinal cord: $i$ situ hybridization experiments with digoxigenin-conjugated antisense riboprobe $(a, b, d-h)$ and with corresponding sense probe $(c, i)$. Developmental stages: $a, \mathrm{E} 6 ; b$ and $c, \mathrm{E} 10 ; d, \mathrm{E} 12 ; e, \mathrm{E} 14 ; f, \mathrm{E} 16 ; g, \mathrm{E} 18 ; h$ and $i$, E20. Arrows point laterally to motoneuron containing ventral horn and motor columns. Note the rapid decline of the specific hybridization signal between E14 $(e)$ and E18 $(g)$. No specific hybridization signal was detectable at E20 $(h, i)$. $e-i$, part of spinal cord containing right ventral horn shown in the figures. Scale bar, $100 \mu \mathrm{m}$.

we analyzed motoneuron levels of the message for T $\alpha 1$, an $\alpha$ tubulin isoform that is exclusively expressed in neurons and whose expression correlates with axonal growth and with reactive sprouting (Miller and Milner, 1987; Matthew and Miller, 1990). As shown in Figure 5, the distribution of T $\alpha 1$ mRNA in postnatal rat spinal cord resembled that of the GAP-43 message, with strong signals in ventral horn motoneurons. T $\alpha 1$ message levels declined between P7 and P10-P11, that is, with a time course resembling that observed for GAP-43. Therefore, two GAP mRNAs are downregulated in motoneurons at the onset of the synapse elimination process, that is, long after the initial contact with the target, suggesting that termination of a growth mode in presynaptic neurons may precede or coincide with the elimination process.

Figure 1. Developmental downregulation of GAP-43 in the chick neuromuscular system: double-labeling of hind thigh muscle cryosections with monoclonal antibody against chick GAP-43 (gap, FITC) and RITC- $\alpha$-bungarotoxin (bgt). GAP-43 is present in intramuscular nerves (arrows in $c$ and $f$ and on the presynaptic side of the $\mathrm{nmj}$, whereas $\alpha$-bungarotoxin binds to AChRs, thus visualizing the postsynaptic side of the nmj. Developmental stages: $a, \mathrm{E} 10 ; b, \mathrm{E} 12 ; c, \mathrm{E} 14 ; d, \mathrm{E} 16 ; e, \mathrm{E} 18 ; f, \mathrm{E} 20 ; g, \mathrm{P} 2 ; h, \mathrm{P} 60$. Note the rapid decline of the GAP-43 signal at the nmj between E16 (d) and P2 $(g)$. Scale bar, $50 \mu \mathrm{m}$. 

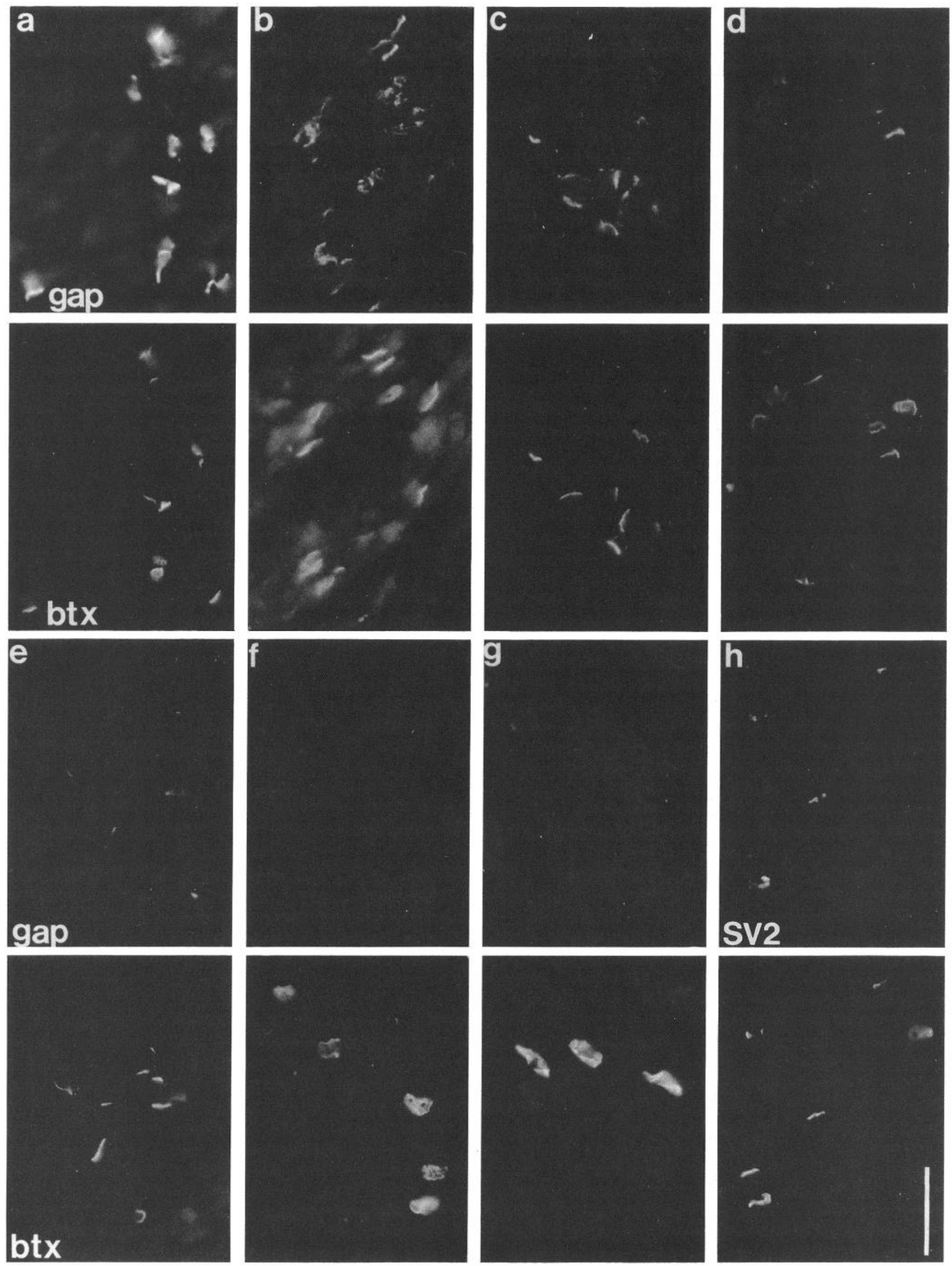

Figure 3. Developmental downregulation of GAP-43 in the rat neuromuscular system: double labeling of hind thigh muscle cryosections with antiserum against rat GAP-43 (gap, FITC) and RITC- $\alpha$-bungarotoxin $(b t x)$. Top panels: $a-g$, GAP-43. $h$, Visualization of nerve terminal with antibody SV2 to synaptic vesicle antigen. Developmental stages: $a, \mathrm{P} 4 ; b, \mathrm{P} 6 ; c, \mathrm{P} 8 ; d, \mathrm{P} 10 ; e, \mathrm{P} 12 ; f, \mathrm{P} 14 ; g$ and $h$, P19. Note the decline of the GAP-43 signal at the nmj between P8 $(c)$ and P14 $(f)$. Scale bar, $65 \mu \mathrm{m}$. 

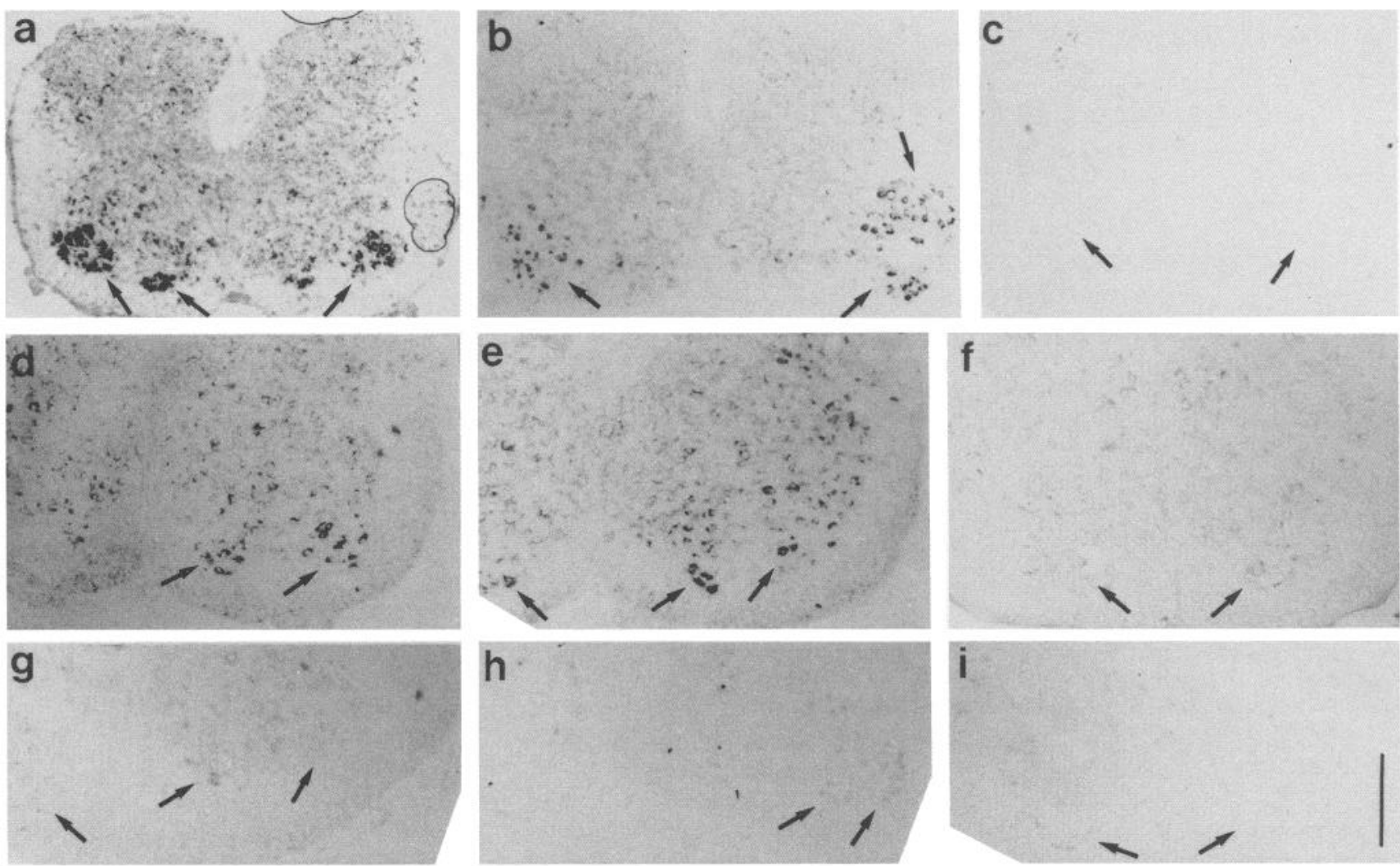

Figure 4. GAP-43 mRNA in the developing rat lumbal spinal cord: in situ hybridization experiments with digoxigenin-conjugated antisense riboprobe $(a, b, d-h)$ and with corresponding sense probe $(c, i)$. Developmental stages: $a, \mathrm{P} 0 ; b$ and $c, \mathrm{P} 4 ; d, \mathrm{P} 8 ; e, \mathrm{P} 9 ; f, \mathrm{P} 10 ; g, \mathrm{P} 11 ; h$ and $i, \mathrm{P} 13$. Arrows point laterally to motoneuron containing ventral horn and motor columns. Note the rapid decline of the specific hybridization signal between P8 $(d)$ and P10 $(f)$. No specific hybridization signal was detectable at P13 $(h, i) . g-i$, part of spinal cord containing right ventral horn shown in the figures. Scale bar, $150 \mu \mathrm{m}$.

\section{Prevention of motoneuron GAP downregulation in the absence of neuromuscular transmission}

Downregulation of GAP messages in spinal motoneurons may be a cell autonomous process, it may reflect developmental events in the spinal cord, or it may be controlled by peripheral processes, that is, by events at the $\mathrm{nmj}$. Due to the coincidence of GAP-43 and T $\alpha 1$ downregulation with synapse elimination, we asked whether blockade of neuromuscular transmission, a procedure that prevents synapse elimination (Thompson et al., 1979; Brown et al., 1981), would affect motoneuron GAP downregulation. Activity blockade was induced by two different procedures: botulinum toxin acts on the presynaptic, cholinergic motoneuron terminal, where it blocks calcium-dependent transmitter release (Kao et al., 1976; Thesleff, 1989), whereas $\alpha$ bungarotoxin acts on the postsynaptic skeletal muscle fiber, where it binds to the $\alpha$-subunit of the AChR and prevents its activation by ligand. Botulinum toxin-induced paralysis of one rat hind limb was obtained by a single local injection at P6, that is, shortly before GAP downregulation and the onset of synapse elimination. Local $\alpha$-bungarotoxin injections, on the other hand, had to be repeated every second day, starting from P6, to block newly inserted AChRs. Both procedures led to strong paralysis of one hind limb with no apparent signs of paralysis in the contralateral control limb. In both cases, paralysis was obvious after about $12 \mathrm{hr}$ and persisted until P20, that is, the latest time point examined in our experiments.
As shown in Figure 6, high levels of GAP-43 immunoreactivity were detected at P13 in intramuscular nerves and nmjs of paralyzed thigh muscle, irrespective of whether paralysis was induced by pre- or postsynaptically acting blocker. GAP-43 signals in P13 paralyzed muscle were comparable or higher than those in P0-P6 rat skeletal muscle, whereas muscles from mockinjected P13 animals (Fig. 6a) or untreated animals (Fig. 3) displayed extremely weak GAP-43 signals. The absence of label with RITC- $\alpha$-bungarotoxin in the ipsilateral muscle of animals treated with this toxin (Fig. $6 d$, bottom) was presumably due to saturation of binding sites with unlabeled toxin. The high GAP43 signals in paralyzed muscle persisted at least until P20 (data not shown, but see Fig. 7e). Surprisingly, significantly elevated GAP-43 signals were also detected in nonparalyzed contralateral muscle (Fig. $6 c, e$ ). This finding was obtained irrespective of whether contralateral muscle was subjected to identical but toxin-free injection protocols with carrier, or whether it was left untreated. However, no elevation of the GAP-43 signal was observed in nonparalyzed, carrier-treated rats, indicating that the contralateral GAP-43 response was due to ipsilaterally injected toxin. That the contralateral effect was not due to systemically acting toxin was suggested by the lack of detectable paralysis signs in that muscle, and by the essentially normal RITC- $\alpha$-bungarotoxin signals in Figure $6 e$ : while injected toxin prevented further binding of RITC- $\alpha$-bungarotoxin to AChRs in ipsilateral muscle (Fig. 6 d), it did not prevent fluorescent toxin binding to contralateral muscle, indicating that it failed 

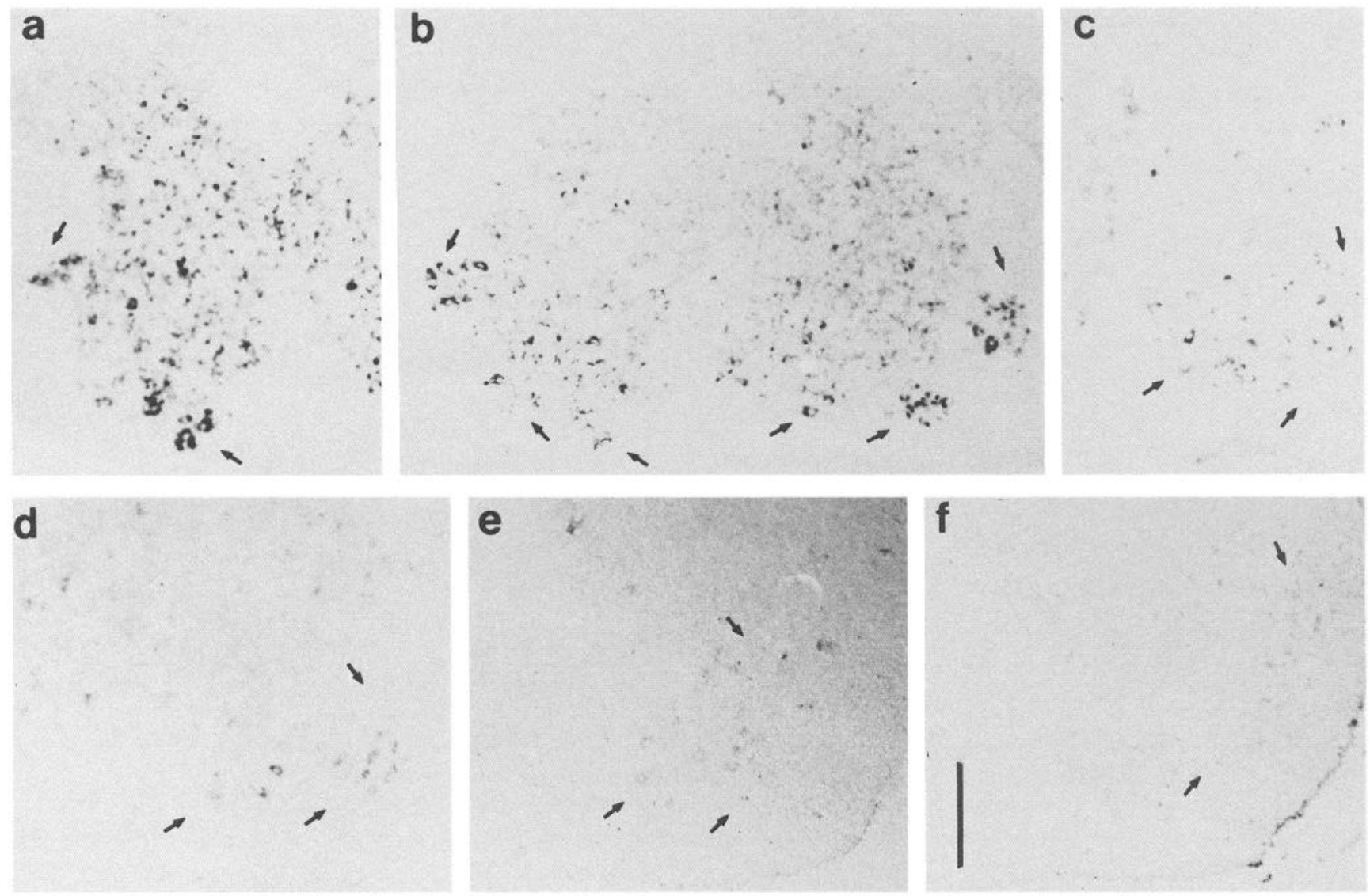

Figure 5. T $\alpha 1$ mRNA in the developing rat lumbal spinal cord: in situ hybridization experiments with digoxigenin-conjugated antisense riboprobe $(a-e)$ and with corresponding sense probe $(f)$. Developmental stages: $a, \mathrm{P} 4 ; b, \mathrm{P} 6 ; c, \mathrm{P} 8 ; d, \mathrm{P} 10 ; e$ and $f$, P12. Arrows point laterally to motoneuron containing ventral horn and motor columns. Note the rapid decline of the specific hybridization signal between P8 $(c)$ and P10 $(d)$. No specific hybridization signal was detectable at $\mathrm{P} 12(e, f) . c-f$, part of spinal cord containing right ventral horn shown in the figures. Scale bar, $150 \mu \mathrm{m}$.

to bind in substantial amounts to AChRs in that muscle. On the other hand, however, only substantial saturation of AChRs by $\alpha$-bungarotoxin produces significant paralysis (Pennefather and Quastel, 1981; Witzemann et al., 1991). Therefore, elevated GAP-43 in the nerves and nmjs of muscles contralateral to paralyzed ones must be explained either by similarly acting, hitherto undescribed additional systemic effects of the toxins or by mechanisms specifically related to paralysis of the ipsilateral muscle. While the first explanation seems unlikely, since no such effects were observed in extensive previous studies with these toxins (Thesleff, 1989), paralysis-related contralateral effects are suggested by the in situ hybridization experiments shown in Figure 7. As expected from the similar behavior of GAP-43 protein and mRNA during development and regeneration, elevated levels of GAP-43 mRNA were detected in the spinal motoneurons that innervated paralyzed muscle (Fig. 7a,b,d,e). Figure $7 a$, however, also shows that significant, although lower amounts of GAP- 43 mRNA were also induced in contralateral ventral horn motoneurons. In addition, further gray matter cells, presumably neurons, displayed elevated GAP-43 signals as a consequence of unilateral botulinum toxin (or $\alpha$-bungarotoxin; data not shown) injection, suggesting that retrograde transneuronal mechanisms may be responsible for these effects. Such mechanisms are particularly effective during development (Jacobson, 1991), and their possible involvement in our paralysis experiments will be discussed in the next section. The in situ hybridization experiments shown in Figure 7 further demonstrate that both motoneuron GAP- 43 and T $\alpha 1$ mRNAs failed to decline when neuromuscular transmission was blocked, and that message levels in animals treated at $\mathrm{P} 6$ remained elevated at least until P20 (Fig. 7e). Therefore, inactivation of neuromuscular transmission in the periphery prevents or counteracts downregulation of motoneuron GAPs, suggesting that downregulation of GAPs at the onset of synapse elimination may be under the control of events in the target region. In addition, these results suggest that GAP mRNAs in motoneurons may be affected by activity-dependent target-derived factors.

\section{Elevated muscle IGFI mimics the effect of paralysis on motoneuron GAP downregulation}

Muscle IGF1 and IGF2 mRNAs decline in parallel with the elimination of polyinnervation and are reinduced by paralysis or denervation (Glazner and Ishii, 1989; Ishii, 1989). In addition, elevated levels of IGF1 or IGF2 in otherwise untreated adult skeletal muscle are sufficient to induce intramuscular nerve sprouting (Caroni and Grandes, 1990). We therefore determined whether maintenance of elevated intramuscular IGF1 during the synapse elimination period was sufficient to reproduce the effects of paralysis on motoneuron GAPs. For this purpose, we applied local unilateral nonlesioning subcutaneous injections of the IGF1 derivative long- ${ }^{3} \mathrm{R}-\mathrm{IGF} 1$ over rat gluteus muscle. Injections were started at P6 and repeated every second day, until 

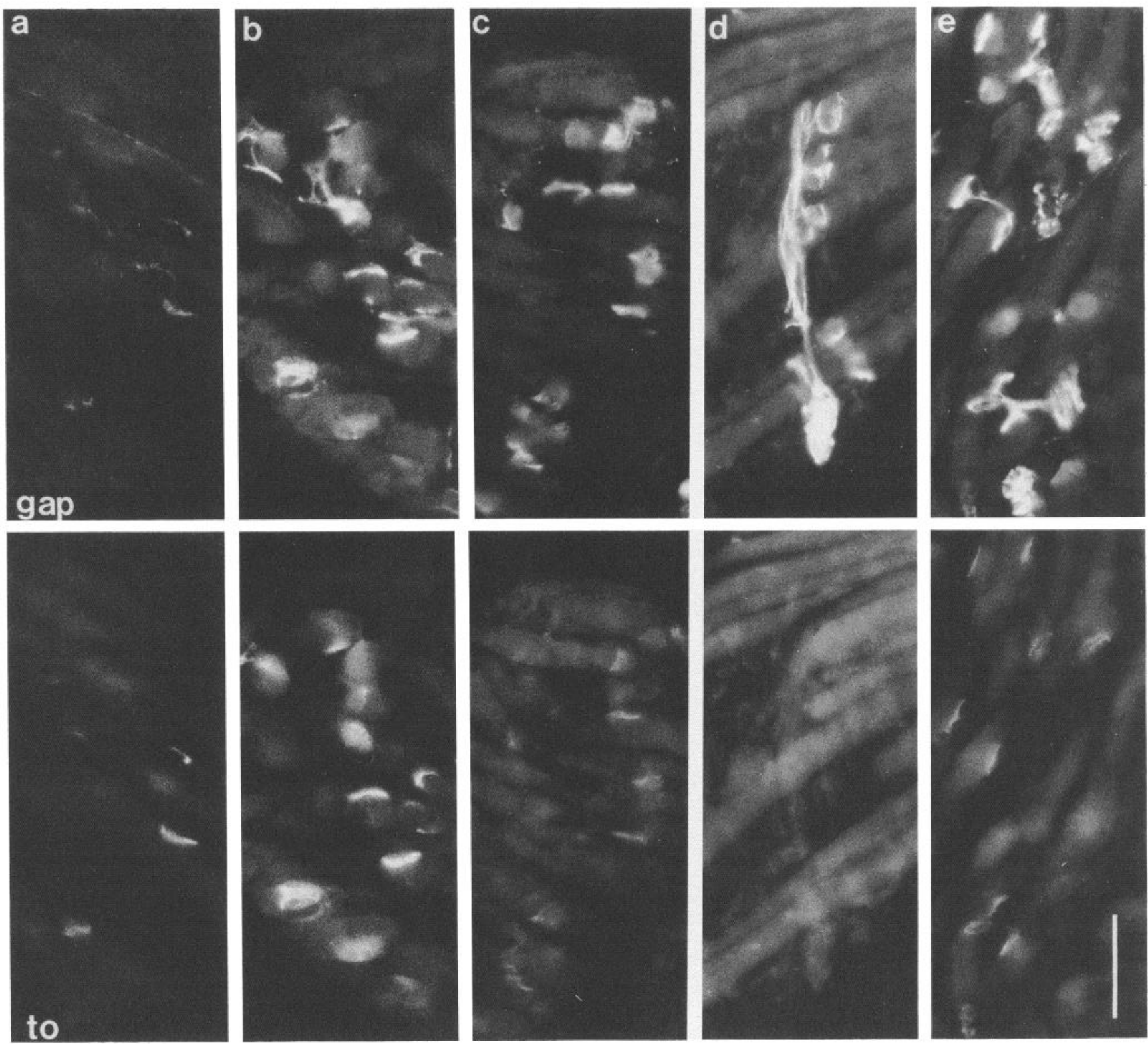

Figure 6. Paralysis prevents the developmental downregulation of GAP-43 in the rat neuromuscular system: double labeling experiments showing GAP-43 (gap, top panels) and AChRs (to, bottom panels). Due to saturation of binding sites by injected nonlabeled toxin, the $\alpha$-bungarotoxin signal in $d$ is not detectable. All sections were from P13 hind thigh muscle. $a$, Carrier-exposed muscle from nonparalyzed animal. $b$ and $c$, Botulinum toxin-induced paralysis (presynaptic block), ipsilateral paralyzed $(b)$ and contralateral nonparalyzed $(c)$ muscle. $d$ and $e, \alpha$-Bungarotoxin-induced paralysis (postsynaptic block), ipsilateral paralyzed $(d)$ and contralateral nonparalyzed $(e)$ muscle. Note the strong GAP-43 signals in both ipsi- and contralateral muscles of unilaterally paralyzed animals. Scale bar, $50 \mu \mathrm{m}$.

P12. Long- ${ }^{-} \mathrm{R}-\mathrm{IGF} 1$ is an 83 amino acid analog of human IGF1 comprising the complete human IGF1 sequence with the substitution of an Arg for the Glu at position 3, and a 13 amino acid extension peptide at the N-terminus. When compared to IGF1, long- ${ }^{3} \mathrm{R}-\mathrm{IGF} 1$ binds with lower affinity to all known IGFbinding proteins, is equally effective in activating the IGF1 receptor, and is therefore more potent in eliciting an IGF1-type response in vitro and in vivo (GroPep product information).

As shown in Figure 8, low amounts of intramuscular long${ }^{3} \mathrm{R}$-IGF1 mimicked the effect of paralysis on motoneuron GAP downregulation: both motoneuron GAP-43 and T $\alpha 1$ mRNAs, and intramuscular nerve and nmj GAP-43 immunoreactivity were elevated in the presence of the growth factor. As in par- alyzed muscle, contralateral elevation of GAPs was also observed. Using the same injection protocol, we have demonstrated in a previous study that the injection of 10 -fold higher amounts of ${ }^{125}$ I-IGF1 did not result in spreading of the growth factor to the contralateral limb (Caroni and Grandes, 1990). In fact, that study demonstrated efficient retention of injected growth factor in underlying muscle, clearance of tracer in the liver, and complete absence of tracer in most organs, including contralateral muscle (Caroni and Grandes, 1990). It seems therefore unlikely that the contralateral effects on GAPs were due to injected long${ }^{3} \mathrm{R}-\mathrm{IGF} 1$ acting systemically. In conclusion, our results demonstrate that both paralysis and elevated muscle IGF1 prevent motoneuron GAP downregulation, suggesting that declining 

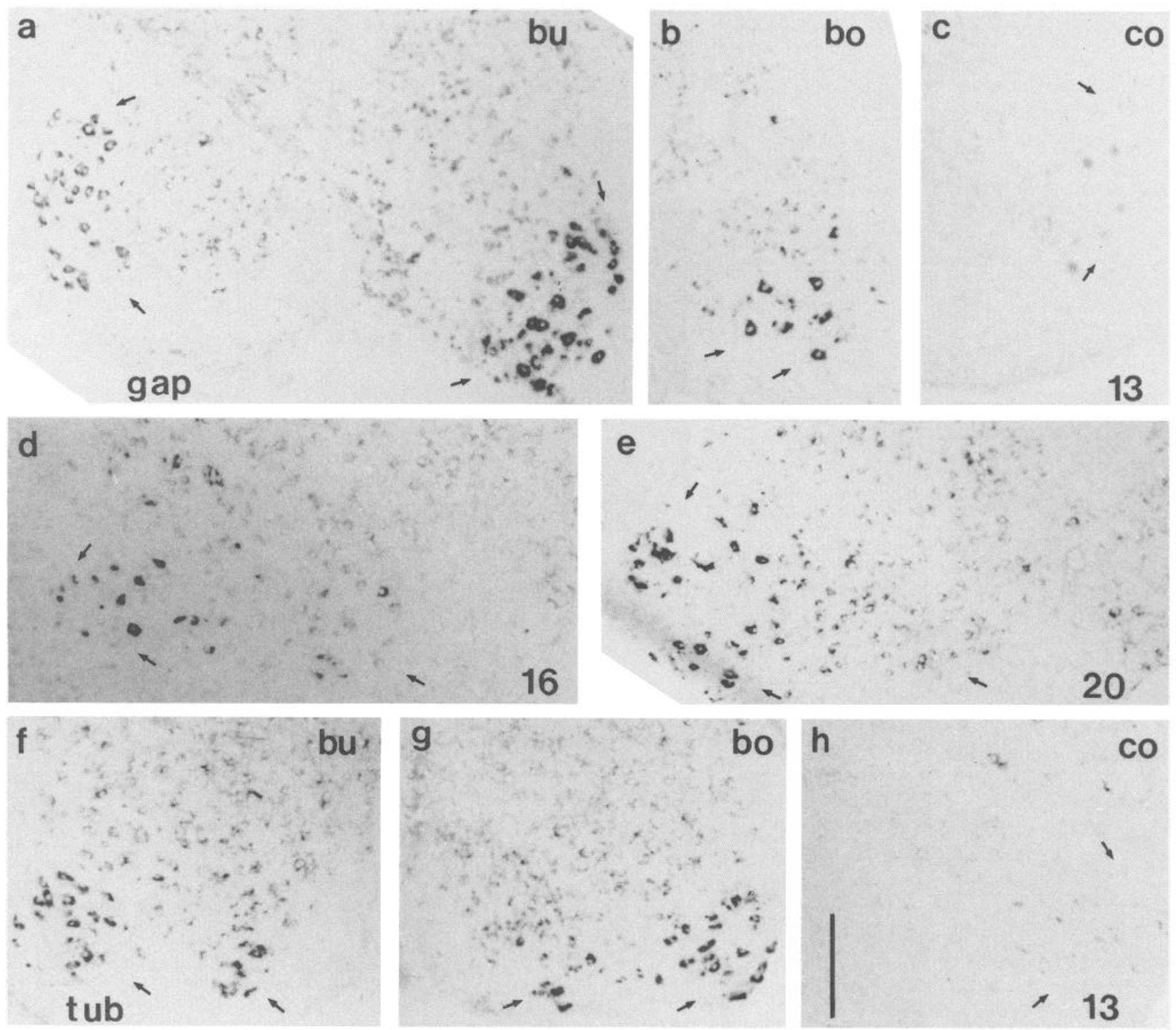

Figure 7. Prevention of developmental GAP mRNA downregulation in spinal cord motoneurons by botulinum toxin (bo) or $\alpha$-bungarotoxin (bu)mediated paralysis at P6. co, control untreated animals. $a-e, G A P-43 \mathrm{mRNA}$ (gap) in lumbar spinal cord motoneurons at P13 (a-c), P16 (d, botulinum toxin treated), and P20 (e, botulinum toxin treated). $f-h, \mathrm{~T} \alpha 1$ mRNA $(t u b)$ in P13 motoneurons. Both ipsilateral (paralyzed side, right) and contralateral ventral horns are shown in $a$, whereas only the ipsilateral ventral horns are shown in $b-h$. The arrows point laterally to motor columns. Scale bar. $150 \mu \mathrm{m}$.

muscle IGFs at the onset of the synapse elimination process may be involved in the downregulation of GAP mRNAs in motoneuron cell bodies.

\section{Discussion}

Our results, drawn from studies of both rat and chick, show that downregulation of motoneuron GAPs during development coincides with the onset of synapse elimination. In addition, we found that downregulation depends on synaptic transmission and target activation, and that counteracting the decrease of muscle IGF1 during synapse elimination is sufficient to prevent the developmental downregulation of motoneuron GAPs. We conclude that the final phase of synapse development involves target-dependent presynaptic regulatory mechanisms. In addition, IGF1 emerges as a candidate activity-dependent targetderived signaling factor in $\mathrm{nmj}$ development.

\section{Downregulation of motoneuron GAPs coincides with the} elimination of polyinnervation during development

Downregulation of GAP-43 during late synapse development has been reported in the visual cortex (Neve and Bear, 1989) and in the neuromuscular system (Hesselmans et al., 1989; Reynolds et al., 1991). Similarly, in regenerating systems GAP43 downregulation lags significantly behind target reinnervation (Skene, 1989; Moya et al., 1989). Our study now shows that in the neuromuscular system developmental downregulation is a rapid process, involving both GAP-43 mRNA in motoneuron cell bodies and, with a delay of $2-3 \mathrm{~d}$, the corresponding protein at the $\mathrm{nmj}$.

An important issue is whether GAP-43 downregulation is a gradual process that may start following contact with the target, or whether it is rapid and confined to the period of side branch 
retraction. While it is possible that some GAP-43 decline already took place upon contact with the target, that is, between E6 and E9 in the chick, and E12 and E16 in the rat, our qualitative data clearly show that significant GAP-43 levels persisted until the onset of the synapse elimination process. Moreover, we could not detect a consistent decrease in the in situ hybridization or immunocytochemistry signals between E10 and E14 respectively (E16) in the chick and between P0 and P8 in the rat, suggesting that motoneuron GAP-43 levels remained stable during this period of $\mathrm{nmj}$ maturation. In contrast, subsequent decline of signals to background levels was observed within a period of a few days in both species. Our data therefore indicate that GAP-43 is downregulated in motoneurons at a defined time in development corresponding with the onset of synapse elimination.

Does GAP-43 downregulation correspond to the specific termination of a nerve growth state in motoneurons, or rather, does it coincide with a generic embryonic to adult switch in development? Downregulation was not restricted to GAP-43 as the mRNA for another GAP, T $\alpha 1$ declined with a similar time course. Additional neuronal proteins, including GAP-24, GAP50 , and N-CAM, are expressed when axons grow, downregulated some time after contact with the target, and reinduced during regeneration (Skene, 1989). It will therefore be important to determine whether all these proteins are downregulated at the same time, or whether differences in timing and mechanisms do exist. Conceivably, a number of diverse proteins may be downregulated in the same way. These proteins may also include juvenile proteins such as certain microtubule-associated proteins (Matus, 1988). Downregulation of a large number of diverse juvenile proteins at the onset of the synapse elimination period may indicate that this process corresponds to a general program switch marking the final phase of nervous system development. If, on the other hand, this particular downregulation mechanism should be restricted to few GAP genes like GAP43 and $\mathrm{T} \alpha 1$, downregulation at the onset of synapse elimination may suggest a more specific role for these proteins in growth processes preceding, but possibly not compatible with synapse elimination. Several observations seem to favor the latter possibility. Thus, some GAPs, including $\beta 2$-tubulin and actin, are downregulated shortly after contact with the target has been made, while others like GAP-43 keep being expressed at high levels for significantly longer periods of time during development and regeneration (Tetzlaff et al., 1991). Furthermore, high levels of GAP-43 are maintained in areas of the adult CNS that have been associated with plasticity (Benowitz and Routtenberg, 1987; Neve et al., 1988), suggesting that the function of this protein may not be restricted to axonal growth. In addition, while GAP-43 and $T \alpha 1$ are reinduced in regeneration and sprouting, some juvenile microtubule-associated proteins are not (Matus, 1988), indicating the existence of further differences between a juvenile-adult switch and the regulation of these GAPs. It therefore seems that, as originally proposed by Skene and Willard (Skene and Willard, 1981; Skene, 1989), GAPs like GAP-43 and T $\alpha 1$ may define a unique type of growth mode in neurons. In the neuromuscular system, but possibly also in other systems (Neve and Bear, 1989), this mode would be turned off at the onset of the synapse elimination period, suggesting the existence of a functional relation between a nongrowing mode in presynaptic neurons and the elimination process.

Clearly, an important open question concerns the possible role of presynaptic GAP downregulation in synapse develop-
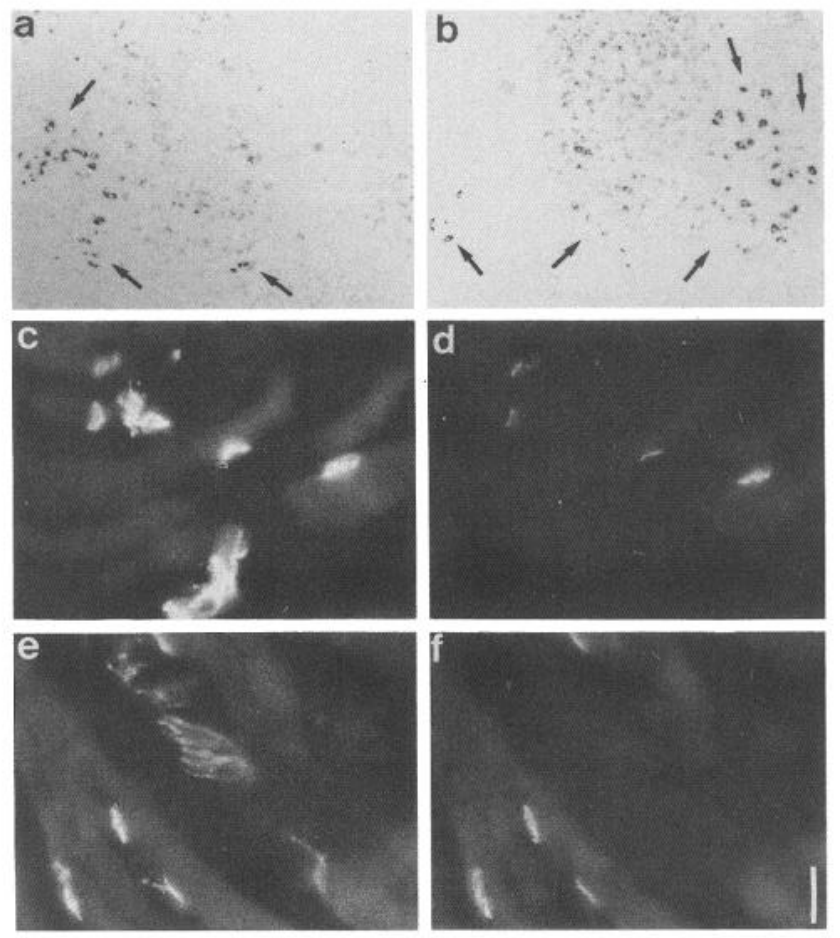

Figure 8. Elevated levels of long- ${ }^{3}$ R-IGF1 in the muscle mimic the effect of paralysis on the developmental downregulation of GAP mRNAs during synapse elimination. The data are from P13 rats that had been injected subcutaneously over one (ipsilateral) gluteus muscle with long${ }^{3} \mathrm{R}-\mathrm{IGF} 1$ every second day. Injections were started at P6, and the contralateral muscle was exposed to carrier. $a$ and $b$, T $\alpha 1(a)$ and GAP-43 (b) mRNA in lumbar spinal cord motoneurons; the ipsilateral ventral horn is to the left in $a$ and to the right in $b . c-f$, Double-labeling experiments: GAP-43 $(c, e)$ and $\alpha$-bungarotoxin binding sites $(d, f)$ in the ipsilateral ( $c, d, I G F 1$ exposed) and contralateral ( $e, f$, control) gluteus muscles. Arrows point laterally to motor columns. Scale bar: $140 \mu \mathrm{m}$ for $a$ and $b ; 22 \mu \mathrm{m}$ for $c-f$.

ment. Our finding that motoneurons contralateral to those projecting to an inactive or IGF1-exposed muscle also express elevated levels of GAP-43 and T $\alpha 1$ implies that it may be possible to determine whether an altered state in presynaptic neurons may affect $\mathrm{nmj}$ development in the contralateral limb. Such experiments, combined with an identification of the type of gene products that fail to be downregulated in contralateral motoneurons, may provide an opportunity to investigate the roles of the presynaptic motoneuron in late synapse development, including synapse elimination.

\section{Levels of GAP-43 and T $\alpha 1$ in motoneurons are regulated by activity and $I G F I$ in the target region}

In the adult nervous system, GAP-43 and T $\alpha 1$ are reinduced when axons restart growing following lesions (Skene and Willard, 1981; Miller and Milner, 1989), and T $\alpha 1$ mRNA is induced when neurons sprout even in the absence of a lesion to the sprouting neuron (Matthew and Miller, 1990). We now demonstrate that GAP-43 and T $\alpha 1$ downregulation in motoneurons during development is prevented in the absence of muscle activation and that this effect can be mimicked by elevated muscle IGF1.

Muscle IGF1 and IGF2 are downregulated during synapse elimination (Glazner and Ishii, 1989; Ishii, 1989), and therefore our findings suggest that declining muscle IGFs may be involved in motoneuron GAP downregulation. Regulation by IGFs may 
involve a direct mechanism requiring interaction with IGF1receptors on motoneuron processes, or it may be indirect, that is, involving signals from intramuscular cells under the influence of IGFs. In a recent study, we found that IGF1 is rapidly upregulated and secreted from adult skeletal muscle fibers in situ following paralysis, and that adult rat motoneurons do express IGF1-receptor mRNA (C. Schneider and P. Caroni, unpublished observations). These findings and the fact that elevated levels of IGFs in adult muscle are sufficient to induce nerve sprouting and intramuscular interstitial cell proliferation (Caroni and Grandes, 1990) support the notion that IGFs may be important activity-regulated target-derived factors in the neuromuscular system.

Both local paralysis and subcutaneous injections of IGF1 produced contralateral effects on motoneuron GAP-43 and T $\alpha 1$. These effects were probably not due to systemic mechanisms because signs of paralysis could exclusively be detected ipsilaterally, we found no evidence for substantial spreading of $\alpha$ bungarotoxin in the postsynaptic blockade experiments, and, applying the same protocol, we demonstrated in a previous study that injected ${ }^{125}$ I-IGF2 failed to spread to the contralateral muscle (Caroni and Grandes, 1990). In addition, the in situ hybridization data indicate that the GAP-43 and T $\alpha 1$ reaction in the spinal cord was not restricted to motoneurons. It therefore seems possible that contralateral reactions were due to the retrograde transmission of a signal by commissural interneurons in the spinal cord. That such mechanisms can operate is indicated by reports of compensatory reactions to target modifications during development (Jacobson, 1991). In addition, specific contralateral sprouting following a unilateral sciatic nerve lesion has been reported (Steinbach, 1981; Ring et al., 1983; Rothshenker and Tal, 1985). In those studies, contralateral reactions were not due to systemic mechanisms: (1) upon denervation of one hind limb, they were exclusively observed in the contralateral hind limb but not in the contra- or ipsilateral front limb (Steinbach, 1981; Rothshenker and Tal, 1985); (2) the reactions were detected significantly earlier when the sciatic nerve was lesioned near to the spinal cord (Rothshenker and Tal, 1985). It was suggested in those studies that the effects were due to transsynaptic mechanisms in the spinal cord and that the mechanisms were retrograde because they were not affected by local rcmoval of sensory afferents (Rothshenker and Tal, 1985). Our findings may be interpreted in a similar manner and may provide molecular markers to study this type of adaptational mechanism.

If retrograde transneuronal reactions to deafferentation should indeed produce macroscopic reactions like contralateral intramuscular nerve sprouting, this may indicate that molecular changes in presynaptic motoneurons may be sufficient to produce reactions in the corresponding muscle. It will therefore be of particular interest to determine the consequences of ipsilateral local paralysis or elevated muscle IGF1 on contralateral $\mathrm{nmj}$ development. Such experiments may yield insights on the possible functional relevance of GAP downregulation at the onset of synapse elimination.

\section{References}

Baizer L, Alkan S, Stocker K, Ciment G (1990) Chicken growthassociated protein (GAP)-43: primary structure and regulated expression of mRNA during embryogenesis. Mol Brain Res 7:61-68.

Basi GS, Jacobson RD, Virag I, Schilling J, Skene JHP (1987) Primary structure and transcriptional regulation of GAP-43, a protein associated with nerve growth. Cell 49:785-791.
Bennet MR (1983) Development of neuromuscular synapses. Physiol Rev 63:915-1048.

Benowitz LI, Routtenberg A (1987) A membrane phosphoprotein associated with neural development, axonal regeneration, phospholipid metabolism, and synaptic plasticity. Trends Neurosci 10:527531

Brown MC, Jansen JKS, Van Essen D (1976) Polyneuronal innervation of skeletal muscle in new-born rats and its elimination during maturation. J Physiol (Lond) 261:387-422.

Brown MC, Holland RL, Hopkins WG (1981) Restoration of focal multiple innervation in rat muscle by transmission block during a critical stage of devclopment. J Physiol (Lond) 318:355-364.

Buckley K, Kelly RB (1985) Identification of a transmembrane glycoprotein specific for secretory vesicles of neuronal and endocrine cells. J Cell Biol 100:1284-1294.

Caroni P, Grandes P (1990) Nerve sprouting in innervated adult skeletal muscle induced by exposure to elevated levels of insulin-like growth factors. J Cell Biol 110:1307-1317.

Coggins PJ, Zwiers H (1991) B-50 (GAP-43): biochemistry and functional neurochemistry of a neuron-specific phosphoprotein. J Neurochem 56:1095-1106.

Cox KH, Angerer RC (1984) Detection of mRNAs in sea urchin embryos by in situ hybridization using asymmetric RNA probes. Dev Biol 101:485-502.

Dahm LM, Landmesser LT (1991) The regulation of synaptogenesis during normal development and following activity blockade. J Neurosci 11:238-255.

Dennis MJ (1981) Development of the neuromuscular junction, inductive interactions between cells. Annu Rev Neurosci 4:43-68.

Glazner GW, Ishii DN (1989) Relationship of insulin-like growth factor 1 mRNA content to synaptogenesis in rat skeletal muscle. Soc Neurosci Abstr 15:1353.

Hesselmans LF, Jennekens FG, vandenOord CJ, Oestreicher AB, Veldman H, Gispen WH (1989) A light and electron microscopic study of B-50 (GAP-43) in human intramuscular nerve and neuromuscular junctions during development. J Neurol Sci 89:301-311.

Ishii DN (1989) Relationship of insulin-like growth factor 2 gene expression in muscle to synaptogenesis. Proc Natl Acad Sci USA 86: 2898-2902.

Jacobson M (1991) Developmental neurobiology. London: Plenum.

Jacobson RD, Virag I, Skene JHP (1986) A protein associated with axon growth, GAP-43, is widely distributed and developmentally regulated in rat CNS. J Neurosci 6:1843-1855.

Kao I, Drachman DB, Price DL (1976) Botulinum toxin, mechanism of presynaptic blockade. Science 193:1256-1258.

Matthew TC, Miller FD (1990) Increased expression of T $\alpha 1 \alpha$-tubulin mRNA during collateral and NGF-induced sprouting of sympathetic neurons. Dev Biol 141:84-92.

Matus A (1988) Microtubule-associated proteins: their potential role in determining neuronal morphology. Annu Rev Neurosci 11:29-44.

Meiri KF, Pfenninger KH, Willard MB (1986) Growth-associated protein, GAP-43, a polypeptide that is induced when neurons extend axons, is a component of growth cones and corresponds to pp46, a major polypeptide of a subcellular fraction enriched in growth cones. Proc Natl Acad Sci USA 83:3537-3541.

Miller FD, Milner RJ (1987) Isotypes of $\alpha$-tubulin are differentially regulated during neuronal maturation. J Cell Biol 105:3065-3073.

Miller FD, Milner RJ (1989) Rapid induction of the major embryonic $\alpha$-tubulin mRNA, T $\alpha 1$, during nerve regeneration in adult brain. $\mathrm{J}$ Neurosci 9:1452-1463.

Moslich E, Fagan AM, Terry RD, DeTeresa R, Mallory M, Gage FH (1991) Reactive synaptogenesis assessed by synaptophysin immunoreactivity is associated with GAP-43 in the dentate gyrus of the adult rat. Exp Neurol 113:131-142.

Moya KL, Ihaveri S, Schneider GE, Benowitz LI (1989) Immunohistochemical localization of GAP-43 in the developing hamster retinofugal pathway. J Comp Neurol 288:51-58.

Nelson RB, Linde DJ, Hyman C, Pfenninger KH, Routtenberg A (1989) The two major phosphoproteins in growth cones are probably identical to two protein kinase $C$ substrates correlated with persistence of long-term potentiation. J Neurosci 9:381-389.

Neve RL, Bear MF (1989) Visual experience regulates gene expression in the developing striate cortex. Proc Natl Acad Sci USA 86:47814784.

Neve RL, Finch EA, Benowitz LI (1988) Growth-associated protein 
GAP-43 is expressed selectively in associative regions of the adult human brain. Proc Natl Acad Sci USA 85:3638-3642.

Pennefather P, Quastel DMJ (1981) Relation between subsynaptic receptor blockade and response to quantal transmitter at the mouse neuromuscular junction. J Gen Physiol 78:313-344.

Reynolds ML, Fitzgerald M, Benowitz LI (1991) GAP-43 expression in developing cutaneous and muscle nerves in the rat hindlimb. Neuroscience 41:201-211.

Ring GD, Reichert F, Rothshenker S (1983) Sprouting in intact sartorius muscles of the frog following contralateral axotomy. Brain Res 60:313-316

Rothshenker S, Tal M (1985) The transneural induction of sprouting and synapse formation in intact mouse muscles. J Physiol (Lond) 360: 387-396.

Skene JHP (1989) Axonal growth-associated proteins. Annu Rev Neurosci 12:127-156.

Skene JHP, Willard MB (1981) Changes in axonally transported proteins during axon regeneration in toad retinal ganglion cells. J Cell Biol 89:86-95.

Skene JHP, Jacobson RD, Snipes GJ, McGuire CB, Norden JI, Freema JA (1986) A protein induced during nerve growth (GAP-43) is a major component of growth cone membranes. Science 233:783-786.
Steinbach JH (1981) Neuromuscular junctions and $\alpha$-bungarotoxinbinding sites in denervated and contralateral cat skeletal muscles. J Physiol (Lond) 313:513-528.

Tetzlaff W, Alexander SW, Miller FD, Bisby MA (1991) Response of facial and rubrospinal neurons to axotomy: changes in mRNA expression for cytoskeletal proteins and GAP-43. I Neurosci 11:25282544.

Thesleff S (1989) Botulinal neurotoxins as tools in studies of synaptic mechanisms. Q J Exp Physiol 74:1003-1017.

Thompson W, Kuffler DK, Jansen JKS (1979) The effect of prolonged, reversible block of nerve impulses on the elimination of polyneuronal innervation of new-born rat skeletal muscle fibers. Neuroscience 2 : 271-281.

Widmer F, Caroni P (1990) Identification, localization, and primary structure of CAP-23, a particle-bound cytosolic protein of early development. J Cell Biol 111:3035-3047.

Witzemann V, Brenner HR, Sakmann B (1991) Neural factors regulate AChR subunit mRNAs at rat neuromuscular synapses. J Cell Biol 114:125-141. 